\title{
Stabilization of Peat Soil by Using Envirotac
}

\author{
Putri Nur Farah Izzati Norazam ${ }^{1}$, Ismail Bakar ${ }^{1, *}$, Alvin John Lim Meng Siang ${ }^{1}$, and \\ Herman Shah Herman ${ }^{1}$ \\ ${ }^{1}$ Faculty of Civil and Environment Engineering, University Tun Hussein Onn Malaysia, 86400 Parit \\ Raja, Johor, Malaysia
}

\begin{abstract}
Peat soil is wet and soft. It is also known as a very soft and difficult soil with high water and organic content, low shear strength, low bearing capacity and their mechanical chemical and biological properties degenerate with time. The characteristics and geotechnical properties of peat soil are mainly related to its high moisture content and high organic content respectively. This is very challenging to geotechnical engineers and construction industry as peat soil characteristic can cause excessive settlement.Soil stabilisation is the process of improving the engineering properties of the soil which will then in return make it more stable. As a result of soil stabilization, the bearing capacity and the strength of the soil will increase with an added bonus of water tightness, resistance to wash out and other properties which will also be improved. In this research, Envirotac polymer is used as the soil stabilizer which is in a form of liquid. This study is done in order to investigate the optimum mix proportion of Envirotac as a liquid stabilizer on Peat soil. The objective of this study was to determine the strength effects of $15 \%, 30 \%$ and $45 \%$ of Envirotec on peat sample and to investigate the shrinkage effect of stabilizing peat soil by using Envirotac. A mould sample with a diameter of $50 \mathrm{~mm}$ and a height of $100 \mathrm{~mm}$ was prepared. Samples were then tested after 7, 14 and 21 days. The physical properties tests conducted for this research are the Atteberg limits and moisture content test, while the mechanical test was Unconfined Compressive strength (UCS) test. The tests were carried out according to BS 1377: 1990. From the result, 30\% Envirotac on peat sample has higher strength from control sample and more economical compare to use $45 \%$ Envirotac which had greater shrinkage effect
\end{abstract}

\section{Introduction}

Soil stabilization is the recent improvement to a certain desired properties in soil to make it stable and useful for a specific purpose especially construction aspects. Dating back from previous stabilization techniques cannot provide an economical and environmental friendly solutions. In this stabilization method, soil are bonded together using liquid stabilizer. This research will focus on establishing peat profile at Gamuda Development Land Jalan Sri Cheeding, Jenjarom Dengkil,Selangor. This is an industrial based laboratory research

*Corresponding author: bismail@uthm.edu.my 
project which is mainly related to experimental works in the usage of Envirotac soil stabilizer to increase the strength of peat soil on site. It is because Envirotac can increase the economical functions and sustain the environment aspects in the investigations. However, when volume of water is reduce to a shrinkage limit, the linear shrinkage of Envirotac peat soil may decrease in one dimension on a soil mass, commonly expressed as a percentage of the original dimension. It was clearly determined according to BS 1377: Part 2: 1990 [1].

\section{Methodology}

The determination of the material and testing of the peat soil sample with suitable are important to obtained data for analysis purposes. Undisturbed soil is used as control sample of the research. This research has conducted physical test and mechanical test. For physical test is atterberg limit, meanwhile mechanical test is unconfined compressive strength (ucs) and linear shrinkage test.

\subsection{Envirotac}

Envirotac is a unique soil stabilizer, dust and erosion control product. Envirotac commonly in liquid form and it is white colour. During drying process, it binds the soil particles together by forming a clear plastic and resin bond. Besides, envirotac also can be use effectively on in-situ material such as sand soil,laterite soil, sily and. Envirotac also confirmed as non-toxic, non-hazardous, environmentally safe dust control which is concentrated liquid format and finally cured in solid state. However, it is still considered as new material in this field, research on this soil stabilizers is yet to be discovered. Fig. 1 shows Envirotac, soil stabilizer in liquid form.

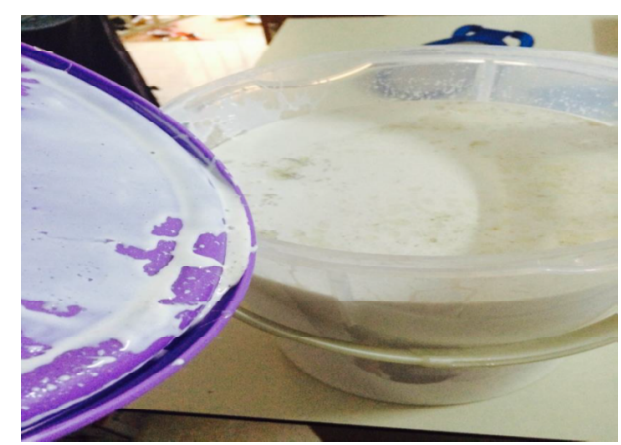

Fig. 1. Envirotac soil stabilizer in liquid form

\subsection{Soil Sample preparation}

Preparation of soil sample for this study were strictly complied to [1] and ASTM D1997 Standards. This study are focus on several testing to identify the physical and chemical characteristics of the sample. Intially, the peat soil sample will be mixed with different percentages of Envirotac and disttiled water. This sample undergo several test to determine its effectiveness and performance of stabilised peat soil. Table 1 shows sample informations. 
Table 1. Samples of information

\begin{tabular}{|c|c|c|c|c|}
\hline Type of Soil & Additives & \multicolumn{3}{|c|}{ Number of samples } \\
\cline { 3 - 5 } & & 7 days & 14 days & 21 days \\
\hline \multirow{3}{*}{ Peat Soil } & Blank & 3 & 3 & 3 \\
\cline { 2 - 5 } & $15 \%$ Envirotac & 3 & 3 & 3 \\
\cline { 2 - 5 } & $30 \%$ Envirotac & 3 & 3 & 3 \\
\cline { 2 - 5 } & $45 \%$ Envirotac & 3 & 3 & 3 \\
\hline
\end{tabular}

\subsection{Atterberg limit}

Atterberg limit is used to determine the water content corresponding to different state of soil. The testing that conducted for this study is moisture content (MC), liquid limit (LL) and the plastic limit (PL). It has physical meanings for remoulded fine grained mineral soils and they correlate with many fundamental soil parameters used in design and construction practice [4]. LL test is repeated with same soil which is peat soil with addition of distilled water, meanwhile PL test is cannot be determine if peat soil is cohesion less [5].

\subsection{Unconfined compressive strength (UCS) test}

The purpose of this test is to determine the soil strength for civil engineering purposes according to Clause BS 1377: 1990 Part 7. Prepare a cylindrical sample which is then subject to increasing axial compression until failure occurs. UCS is the highest load that could be attain per unit area on a cylindrical sample tested in compression. Fig. 2 shows UCS Test equipment.

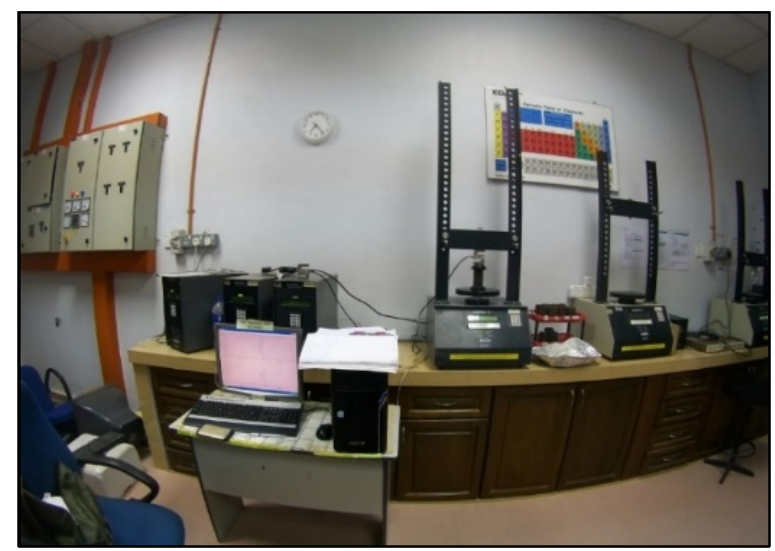

Fig.2 UCS test equipment

\subsection{Linear shrinkage test}

Linear shrinkage test is conducted using standard semi-circular linear shrinkage moulds of $25 \mathrm{~mm}$ diameter x $140 \mathrm{~mm}$ length in accordance to BS 1377:1990 (Test 5). The test aimed to examine the reduction in linear shrinkage of stabilized peat in comparison to that untreated peat. Fig. 3 shows linear shrinkage test of the sample. 


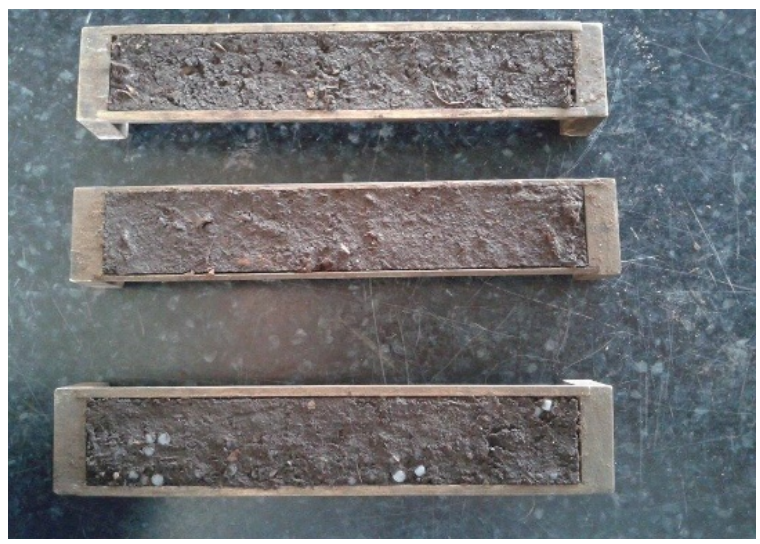

Fig. 3. Linear shrinkage test of the sample

\section{Result}

The experiment was conducted in Research Center Soft Soil (RECESS), Universiti Tun Hussein Onn Malaysia. The result are shown clearly from the analysis of graphs. Unicofined compressive strength between the control specimens and specimens containing substituents, and the shrinkage effect of the envirotac into the peat soil was analyzed.

\subsection{Alterbert limit test}

For this test, the moisture content of the soil is $237 \%$. From the data, it can be classified as peat soil due to it is range $200 \%$ - 700\% [3]. Table 2 shows moisture content of the soil sample. Next, the liquid limit test was conducted based on BS1377: Part 2: 1990: 4.3 The liquid limit percentages of the peat soil sample is $264 \%$ while the plastic limit percentages is $139 \%$. The data obtained shows that liquid limit and plastic limit is high and can be categorized as peat [2],[6]. Table 3(a) shows plastic limit of the soil sample, Table 3(b) shows liquid limit of the soil sample and Figure 4 shows the liquid limit of the soil sample.

Table 2. Moisture content of the soil sample

\begin{tabular}{|c|c|c|c|}
\hline Container No & 1 & 2 & 3 \\
\hline Wet soil + container (g), m2 & 55.54 & 55.31 & 55.18 \\
\hline Dry soil + container (g), m3 & 20.73 & 20.63 & 20.91 \\
\hline Container (g), m1 & 6.12 & 6.27 & 6.32 \\
\hline Moisture Loss (g), m2-m3 & 34.81 & 34.68 & 34.27 \\
\hline Dry soil (g), m3-m1 & 14.61 & 14.36 & 14.68 \\
\hline Moisture Content $(\%)$ & 238.3 & 241.5 & 233.4 \\
\hline Average Moisture Content (\%) & \multicolumn{3}{|c|}{237} \\
\hline
\end{tabular}


Table 3(a). Plastic limit of the soil sample

\begin{tabular}{|c|c|c|}
\hline Test Number & $\mathbf{1}$ & $\mathbf{2}$ \\
\hline Mass of Can + Moist Soil, $\mathbf{M}_{\mathbf{c w s}}(\mathbf{g})$ & 20.76 & 20.63 \\
\hline Mass of Can + Dry Soil, $\mathbf{M}_{\mathbf{c s}}, \mathbf{( g )}$ & 15.28 & 12.05 \\
\hline Mass of Can $\mathbf{M}_{\mathbf{c}}(\mathbf{g})$ & 5.35 & 5.86 \\
\hline Mass of Dry Soil, $\mathbf{M}_{\mathbf{s}}(\mathbf{g})$ & 6.46 & 6.19 \\
\hline Mass of water, $\mathbf{M}_{\mathbf{w}} \mathbf{( g )}$ & 8.95 & 8.58 \\
\hline Water content,w $\mathbf{( \% )}$ & 138.5 & 138.6 \\
\hline
\end{tabular}

Table 3(b). Liquid limit of the soil sample

\begin{tabular}{|c|c|c|c|c|c|c|c|c|}
\hline Test Number & \multicolumn{2}{|c|}{1} & \multicolumn{2}{|c|}{2} & \multicolumn{2}{|c|}{3} & \multicolumn{2}{|c|}{4} \\
\hline $\begin{array}{l}\text { Dial Gauge Reading (Start) } \\
\text { (mm) }\end{array}$ & 0 & 0 & 0 & 0 & 0 & 0 & 0 & 0 \\
\hline $\begin{array}{l}\text { Dial Gauge Reading (End) } \\
\text { (mm) }\end{array}$ & 15.1 & 15.2 & 18.0 & 18.1 & 21.1 & 21.2 & 24.3 & 24.2 \\
\hline Cone Penetration (mm) & 15.1 & 15.2 & 18.0 & 18.1 & 21.1 & 21.2 & 24.3 & 24.2 \\
\hline Average penetration (mm) & \multicolumn{2}{|c|}{15.15} & \multicolumn{2}{|c|}{18.05} & \multicolumn{2}{|c|}{21.15} & \multicolumn{2}{|c|}{24.25} \\
\hline Can Number & \multicolumn{2}{|c|}{$\mathbf{A}$} & \multicolumn{2}{|c|}{ B } & \multicolumn{2}{|c|}{ C } & \multicolumn{2}{|c|}{ D } \\
\hline $\begin{array}{l}\text { Mass of Can + Moist Soil, } \\
M_{c w s}(g)\end{array}$ & \multicolumn{2}{|c|}{41.03} & \multicolumn{2}{|c|}{41.04} & \multicolumn{2}{|c|}{40.24} & \multicolumn{2}{|c|}{40.52} \\
\hline $\begin{array}{l}\text { Mass of Can + Dry Soil, } M_{c s}, \\
\text { (g) }\end{array}$ & \multicolumn{2}{|c|}{15.28} & \multicolumn{2}{|c|}{15.23} & \multicolumn{2}{|c|}{14.82} & \multicolumn{2}{|c|}{14.99} \\
\hline Mass of Can $M_{c}(g)$ & \multicolumn{2}{|c|}{5.42} & \multicolumn{2}{|c|}{5.42} & \multicolumn{2}{|c|}{5.23} & \multicolumn{2}{|c|}{5.43} \\
\hline Mass of Dry Soil, $M_{s}(g)$ & \multicolumn{2}{|c|}{9.86} & \multicolumn{2}{|c|}{9.81} & \multicolumn{2}{|c|}{9.59} & \multicolumn{2}{|c|}{9.56} \\
\hline Mass of water, $M_{w}(g)$ & \multicolumn{2}{|c|}{25.75} & \multicolumn{2}{|c|}{25.81} & \multicolumn{2}{|c|}{25.42} & \multicolumn{2}{|c|}{25.53} \\
\hline Water content, w (\%) & \multicolumn{2}{|c|}{261.2} & \multicolumn{2}{|c|}{263.1} & \multicolumn{2}{|c|}{265.1} & \multicolumn{2}{|c|}{267.1} \\
\hline
\end{tabular}

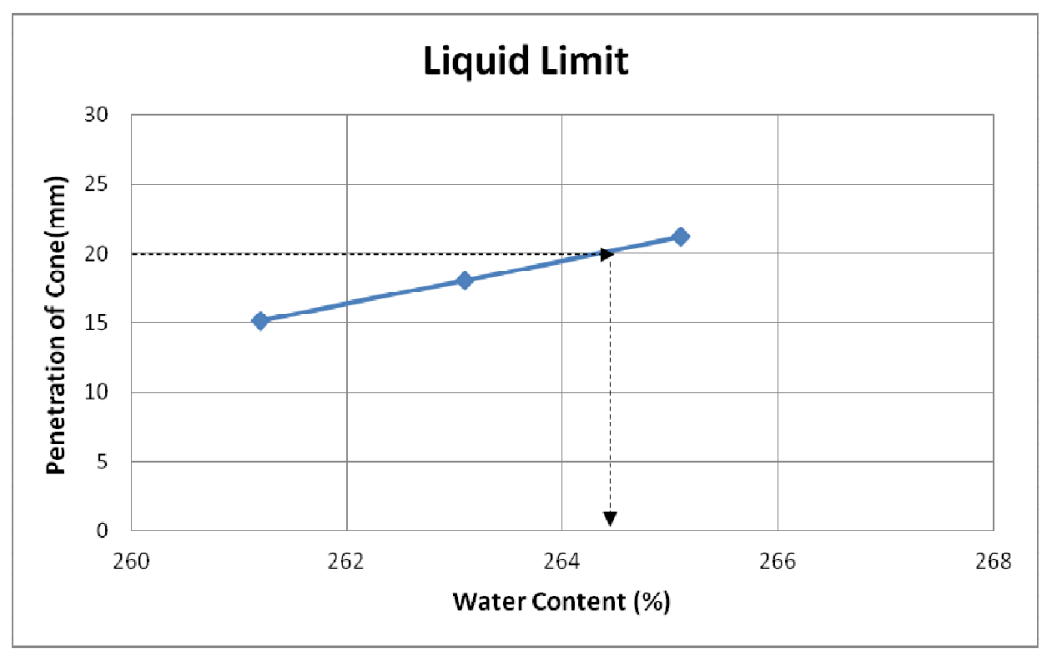

Fig. 4. Liquid limit of the soil sample

\subsection{Analysis of unconfined compressive strength test}

UCS test was performed on the cured peat soil sample with different percentages of stabilizer. In this research, the standard curing (air curing technique) were used during 
sample preparation. From the data, the strength of the peat soil with Envirotac was increases as the percentage Envirotac in the peat soil sample increases. It is because the addictive was homogenously bond together with the peat soil sample. Table 4 shows result of the peat soil sample with the Envirotac meanwhile Fig. 5 shows unconfined compressive strength of peat soil with Envirotac curing time.

Table 4. Result of the peat soil sample with Envirotac.

\begin{tabular}{|c|c|c|c|c|}
\hline Type of Soil & Additives & \multicolumn{3}{|c|}{ Unconfined Compressive Strength (kPa) } \\
\cline { 3 - 5 } & & $\mathbf{7 ~ d a y s}$ & $\mathbf{1 4}$ days & $\mathbf{2 1}$ days \\
\hline \multirow{3}{*}{ Peat Soil } & Blank & 42.46 & 44.84 & 46.31 \\
\cline { 2 - 5 } & $15 \%$ Envirotac & 175.81 & 405.53 & 501.27 \\
\cline { 2 - 5 } & $30 \%$ Envirotac & 241.87 & 537.34 & 561.72 \\
\cline { 2 - 5 } & $45 \%$ Envirotac & 422.95 & 560.55 & 573.89 \\
\hline
\end{tabular}

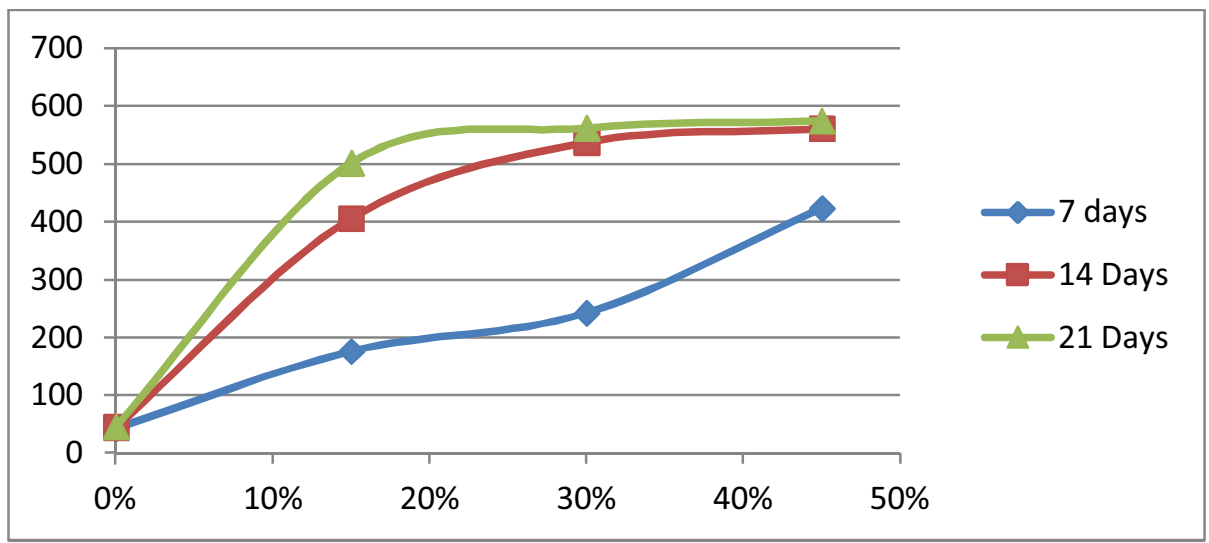

Fig. 5. Unconfined compressive strength of peat soil sample with Envirotac curing time.

\subsection{Analysis of linear shrinkage test}

This test aimed to determine the reduction in linear shrinkage of stabilized peat in comparison to that untreated sample, treated with polymer which is Envirotac. From the result, the addition of Envirotac into soil sample make it more compact. Besides, it is also homogeneous.

Table 5. Linear Shrinkage of the Sample

\begin{tabular}{|c|c|c|c|}
\hline Sample & $\begin{array}{c}\text { Length of } \\
\text { mould, L (mm) }\end{array}$ & $\begin{array}{c}\text { Longitudinal shrinkage of the } \\
\text { specimen, Ls (mm) }\end{array}$ & $\begin{array}{c}\text { Linear Shrinkage, } \\
\text { LS (\%) }\end{array}$ \\
\hline Peat & 140.22 & 118.80 & 15.28 \\
\hline Peat $+15 \%$ Envirotac & 140.51 & 116.34 & 17.20 \\
\hline Peat $+30 \%$ Envirotac & 140.43 & 115.10 & 18.04 \\
\hline Peat $+45 \%$ Envirotac & 140.33 & 110.64 & 21.16 \\
\hline
\end{tabular}




\section{Conclusion}

As conclusion, the addition of the Envirotac into peat soil can increase the strength of peat soil sample. However, the shrinkage of the peat soil will increase as the addictive react with it. The best percentage of the Envirotac in the peat soil is $30 \%$. The strength of $45 \%$ of the Envirotac in the peat soil is the highest. However, it is suffered a lot of shrinkage rather than $30 \%$ of the Envirotac in the peat soil. Besides, the strength of $30 \%$ and $45 \%$ Envirotac after 21 days curing time is almost similar. From here, it can be more costly for treat the peat soil.

Next, this research still new in this field and a lot of improvement must be carry out near future. As the recommendation, Envirotac must be mix with other material to control the shrinkage of the peat soil. High Density Polyethylene (HDPE) is can be use one of the solution to control the shrinkage of the sample with Envirotac.

\section{References}

[1] BS 1377, Methods of test for soils for civil engineering purposes, British Standard Institution, London, (1990)

[2] B.B.K. Huat, S. Kazemian, A. Asadi, A. Prasad, Geotecnics of organic soils, CRC Press/Balkema, London, (2014)

[3] B. Huat, Organic and peat soils engineering, International Standard Book Number: 983-2871-08-5, (2004)

[4] P. Kolay, Peat stabilization using gypsum and fly ash, UNIMAS E-Journal of Civil Engineering, 1(2), (2010)

[5] P. Kolay, H. Sii, S.Taib, Tropical peat soil stabilization using class F pond ash from coal fired power plant, International Journal of Civil and Environmental Engineering 3(2), (2011)

[6] S.N.M. Razali, I. Bakar, A. Zainorabidin, Behaviour of peat soil in instrumented physical model studies, Procedia Eng., 53, 145-155 (2013) 